\title{
X-ray reflectometry of a platinum coating as reference sample for the ATHENA coating development
}

Jafari, A.; Christensen, F. E.; Massahi, S.; Svendsen, S.; Vu, L. M.; Henriksen, P. L.; Shortt, B.; Krumrey, M.; Cibik, L.; Handick, E.

Total number of authors:

11

Published in:

Optics for EUV, X-Ray, and Gamma-Ray Astronomy IX

Link to article, DOI:

$10.1117 / 12.2527557$

Publication date:

2019

Document Version

Publisher's PDF, also known as Version of record

Link back to DTU Orbit

Citation $(A P A)$ :

Jafari, A., Christensen, F. E., Massahi, S., Svendsen, S., Vu, L. M., Henriksen, P. L., Shortt, B., Krumrey, M., Cibik, L., Handick, E., \& Ferreira, D. D. M.' (2019). X-ray reflectometry of a platinum coating as reference sample for the ATHENA coating development. In S. L. OD., \& G. P. (Eds.), Optics for EUV, X-Ray, and Gamma-Ray Astronomy IX (Vol. 11119, pp. 111191K-111191K-7). SPIE - International Society for Optical Engineering. Proceedings of SPIE - The International Society for Optical Engineering https://doi.org/10.1117/12.2527557

\section{General rights}

Copyright and moral rights for the publications made accessible in the public portal are retained by the authors and/or other copyright owners and it is a condition of accessing publications that users recognise and abide by the legal requirements associated with these rights.

- Users may download and print one copy of any publication from the public portal for the purpose of private study or research.

- You may not further distribute the material or use it for any profit-making activity or commercial gain

- You may freely distribute the URL identifying the publication in the public portal 


\section{X-ray reflectometry of a platinum coating as reference sample for the ATHENA coating development}

A. Jafari, F. E. Christensen, S. Massahi, S. Svendsen, L. M. Vu, et al.

A. Jafari, F. E. Christensen, S. Massahi, S. Svendsen, L. M. Vu, P. L. Henriksen, B. Shortt, M. Krumrey, L. Cibik, E. Handick, D. D. M. Ferreira, "Xray reflectometry of a platinum coating as reference sample for the ATHENA coating development," Proc. SPIE 11119, Optics for EUV, X-Ray, and Gamma-Ray Astronomy IX, 111191K (9 September 2019); doi: 10.1117/12.2527557

SPIE Event: SPIE Optical Engineering + Applications, 2019, San Diego, California, United States 


\title{
X-ray Reflectometry of a Platinum Coating as Reference Sample for the ATHENA Coating Development
}

\author{
A. Jafari ${ }^{\mathrm{a}}$, F. E. Christensen ${ }^{\text {a }}$, S. Massahi ${ }^{\mathrm{a}}$, S. Svendsen ${ }^{\mathrm{a}}$, L. M. Vu ${ }^{\mathrm{a}}$, P. L. Henriksen ${ }^{\mathrm{a}}$, B. \\ Shortt ${ }^{\mathrm{b}}$, M. Krumrey ${ }^{\mathrm{c}}$, L. Cibik ${ }^{\mathrm{c}}$, E. Handick ${ }^{\mathrm{c}}$, and D. D. M. Ferreira ${ }^{\mathrm{a}}$ \\ ${ }^{a}$ DTU Space, Technical University of Denmark, Elektrovej building 327,2800 , Kongens \\ Lyngby, Denmark \\ ${ }^{\text {b} E u r o p e a n ~ S p a c e ~ A g e n c y ~(E S T E C), ~ K e p l e r l a a n ~ 1, ~ P O ~ B o x ~ 299, ~} 2200$ AG, Noordwijk, \\ Netherlands \\ 'Physikalisch-Technische Bundesanstalt (PTB), Abbestraße 2-12, 10587 Berlin, Germany
}

\begin{abstract}
X-ray reflectivity (XRR) characterization of X-ray mirrors is an essential step for designing space telescopes and instruments. We report on production and characterization of platinum thin films coated onto a flat thick glass substrate for evaluating measurement results obtained using several XRR systems. The main objective of this study is to compare the XRR results measured using facilities at the Technical University of Denmark, DTU Space, and BESSY II for the Advanced Telescope for High-ENergy Astrophysics (ATHENA) mission funded by the European Space Agency, ESA. This sample will be used as a reference sample for testing and calibrating similar measurements at relevant X-ray facilities. This information demonstrates the stable performance of the platinum mirror as a reference sample. Also, the overlayer effect on mirror performance is investigated.
\end{abstract}

Keywords: Platinum thin film, X-ray mirror, ATHENA, optics, X-ray reflectivity, overlayer, synchrotron measurement

\section{INTRODUCTION}

ATHENA is an ESA selected large class mission due for launch in the early 2030s ${ }^{1}$. It is evident that XRR measurements are essential and powerful ways to assess the quality of mirrors for any X-ray instruments, such as X-ray telescopes. XRR characterization provides important information on thickness, roughness, density, and the number of layers. ${ }^{2,3}$ Thus precision and accuracy of each parameter is of importance.

Platinum (Pt) as a heat and chemical resistant coating material is applied in a broad range of applications. The excellent properties of this noble material has been extensively studied in several works ${ }^{4-7}$. Pt is used as a multilayer component in the optics of the NuSTAR telescope launched in 2012, working in grazing incidence hard $\mathrm{X}$-ray, up to the Pt K-absorption edge around $79 \mathrm{keV}^{6}$. However, the significant interest in Pt thin films is not limited to space applications and Pt mirrors are widely used in optical elements to focus or cut off high energy synchrotron radiation ${ }^{5}$. Thomsen-Schmidt et al. have reported on metrological characterization of Pt thin films mainly using XRR and spectral ellipsometry ${ }^{8}$. In this study, we investigated the reflectivity performance of $\mathrm{Pt}$ thin films through both energy and angle XRR scans.

For our purpose, $\mathrm{Pt}$ is a suitable coating material to track the reliability and reproducibility of XRR measurements over an extended period of time. In this work, we will report on the design, production, and characterization of a Pt coated mirror applicable in the X-ray facilities where the ATHENA mirrors are (and will be) tested, mainly at DTU Space and the Four-Crystal Monochromator beamline at the Physikalisch-Technische Bundesanstalt (FCM-PTB) at the electron storage ring BESSY II.

Further author information

Atefeh Jafari, atefeh.j87@gmail.com, Telephone: +45 45259788

Desiree Della M. Ferreira, desiree@space.dtu.dk,Telephone: +45 45259762

Optics for EUV, X-Ray, and Gamma-Ray Astronomy IX, edited by Stephen L. O'Dell, Giovanni Pareschi, Proc. of SPIE Vol. 11119, 111191K · C 2019 SPIE · CCC code: 0277-786X/19/\$21 - doi: 10.1117/12.2527557 


\section{EXPERIMENTAL}

\subsection{Design}

The design of the Pt thin film is based on X-ray reflectivity simulations of various film thicknesses and roughness parameters which are related to the number and amplitude of Kiessig fringes, respectively. In the simulations, the surface roughness of the $\mathrm{Pt}$ film was fixed to $0.5 \mathrm{~nm}$ based on the roughness value reported in Soufli $e t a l^{9}$. A simulation of the selected design of $30 \mathrm{~nm} \mathrm{Pt}$ thin film is presented in Figure 1a. Using these condition, results in clear features, Kiessig fringes, for low and high energies. It is necessary to use a very smooth substrate because the fringes becomes less distinct as substrate roughness increases, as shown in Figure 1b.
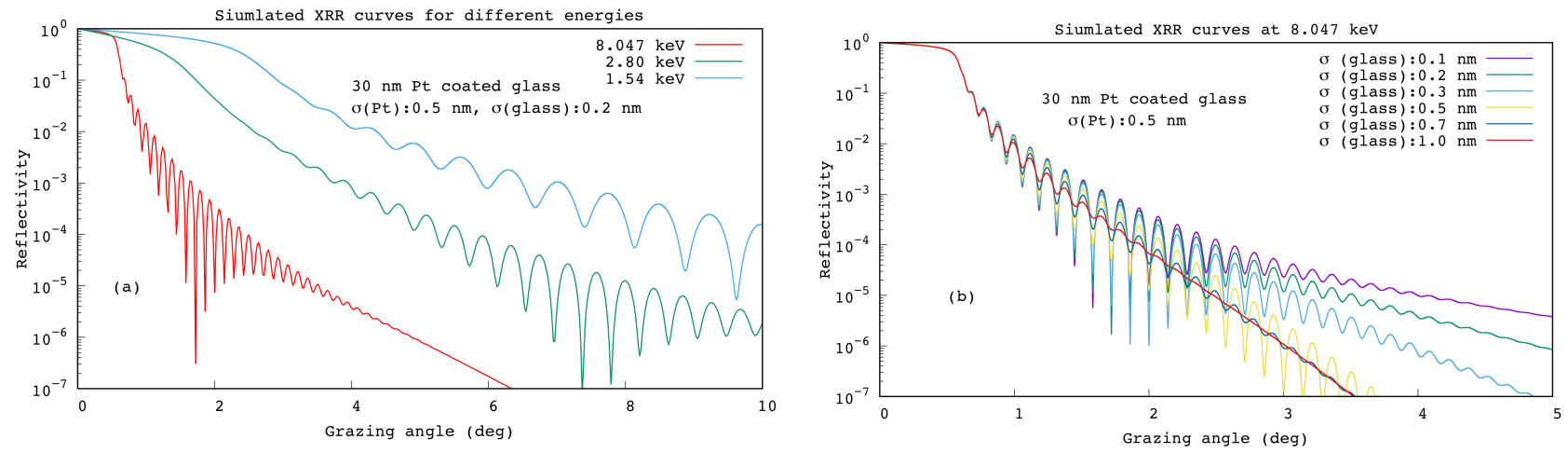

Figure 1: (a) Simulated XRR curves at different energies for a $30 \mathrm{~nm}$ Pt thin film with a fixed Pt roughness $(\sigma)$ of $0.5 \mathrm{~nm}$ coated onto $\mathrm{SiO}_{2}$ (glass) with a roughness of $0.2 \mathrm{~nm}$. (b) The effect of substrate roughness on Kiessig fringes.

\subsection{Fabrication}

A $30 \mathrm{~nm}$ Pt layer was deposited onto a super-polished flat glass substrate made from fused silica (diameter: 101 $\mathrm{mm}$, thickness: $17 \mathrm{~mm}$ ). The substrate surface roughness provided by the manufacturer (Coastline Optics) is $0.1 \mathrm{~nm}$ based on optical profile characterization. Both surfaces are polished to fine ground level. Specifications of the glass substrate with original ID: \#SN85 are listed in Table 1. The SN85 glass sample was coated alongside a $10 * 70 \mathrm{~mm}^{2}$ witness sample ( ID: si6965) diced from a $\sim 0.7 \mathrm{~mm}$ thick double-side polished Si(100) wafer. The witness sample was exposed to plasma cleaning procedure prior to coating while the glass surface was blown with compressed $\mathrm{Ni}$ to preserve the smoothness of the surface. The samples were coated using DC magnetron sputtering facility at DTU Space ${ }^{10}$ using a Pt target with purity of $99.99 \%$. Honeycomb collimation was used to obtain a uniform and smooth thin film ${ }^{11}$. The deposition was performed at a working Ar gas pressure of $(3.0 \pm 0.2) \mathrm{m}$ Torr and discharge power of $300 \mathrm{~W}$. The distance between the target and the sample holder inside the chamber was $155 \mathrm{~mm}$. Figure 2 shows the sample SN85 before and after coating.

Table 1: Specifications list of the glass substrate, provided by the manufacturer.

\begin{tabular}{ll}
\hline \hline Parameter & Specification \\
\hline Material & Corning 7980 fused silica \\
Outer diameter & $101.6 \mathrm{~mm}$ \\
Thickness & $17 \mathrm{~mm}$ \\
Surface flatness & $<=0.10$ Wave PV @ 633 nm in the Clear Aperture \\
Surface roughness & $<=0.1 \mathrm{~nm}$ measured with Zygo 5500 Optical Profiler \\
Surface quality & $10^{-5}$ Scratch-Dig in the Clear Aperture \\
\hline \hline
\end{tabular}




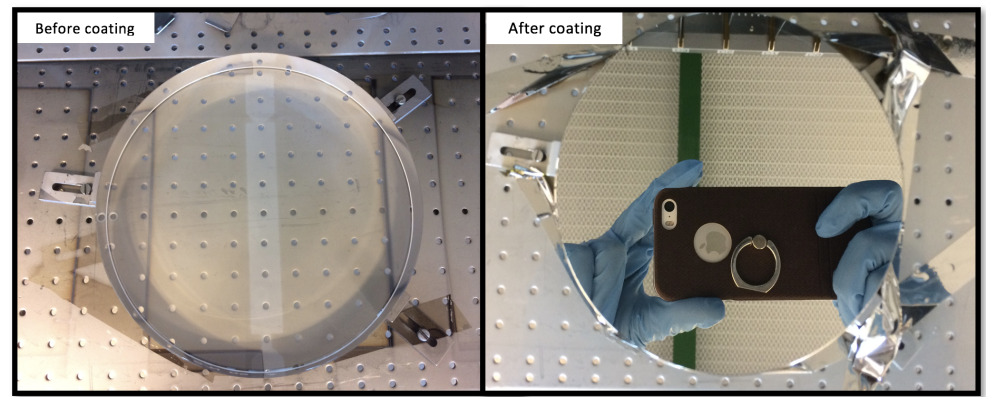

Figure 2: (Left) The superpolished glass substrate SN85 prior to coating. (Right) the Pt thin film surface after coating.

\subsection{Characterization}

We used the XRR facility at DTU Space equipped with $\mathrm{Cu} \mathrm{K}_{\alpha}$ radiation source. In addition, we performed angle scans at $8.047 \mathrm{keV}$ and $3.600 \mathrm{keV}$, as well as energy scans from 3.4-10.0 keV at the FCM beamline in the PTB laboratory at the synchrotron radiation facility BESSY $\mathrm{II}^{12}$. We performed the low-energy angle scans at $3.600 \mathrm{keV}$, the lowest energy we could use without changing the optical elements of the beamline setup.

It is worth mentioning that these samples were intentionally not characterized using other techniques in order to minimize additional contamination effects or possible damage of the surface. These samples are stored at the same conditions as the coated mirror samples for ATHENA are at DTU Space.

\section{RESULTS AND DISCUSSION}

The reflectivity of the samples was measured immediately after coating and after a few months during two beamtimes at the FCM beamline. Consistency of the measured angle scans can be seen in Figure 3. All the XRR curves follow an identical trend revealing the reproducibility of measurements and stability in reflectivity performance of $\mathrm{Pt}$ thin films, as expected. A higher intensity of reflected photons and a better angular resolution was obtained using synchrotron radiation, in particular at high angles, due to the brighter beam and the photodiode detector with better sensitivity.

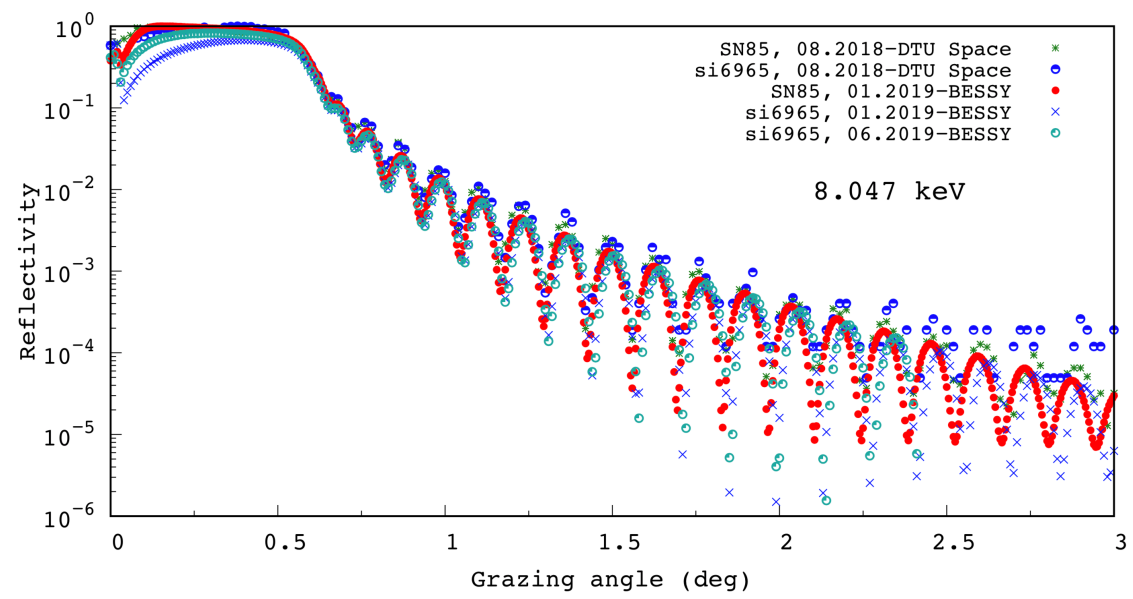

Figure 3: Comparison of the measured XRR of the Pt coated glass SN85 and the witness sample si6965. All scans performed at $8.047 \mathrm{keV}$ using DTU Space and BESSY facilities.

Figure $4 \mathrm{a}$ and $4 \mathrm{~b}$ show angle scan XRR measured for three positions on the Pt coated glass with $40 \mathrm{~mm}$ horizontal distance between each measurement, all positions were vertically centered. Overlapping measured 


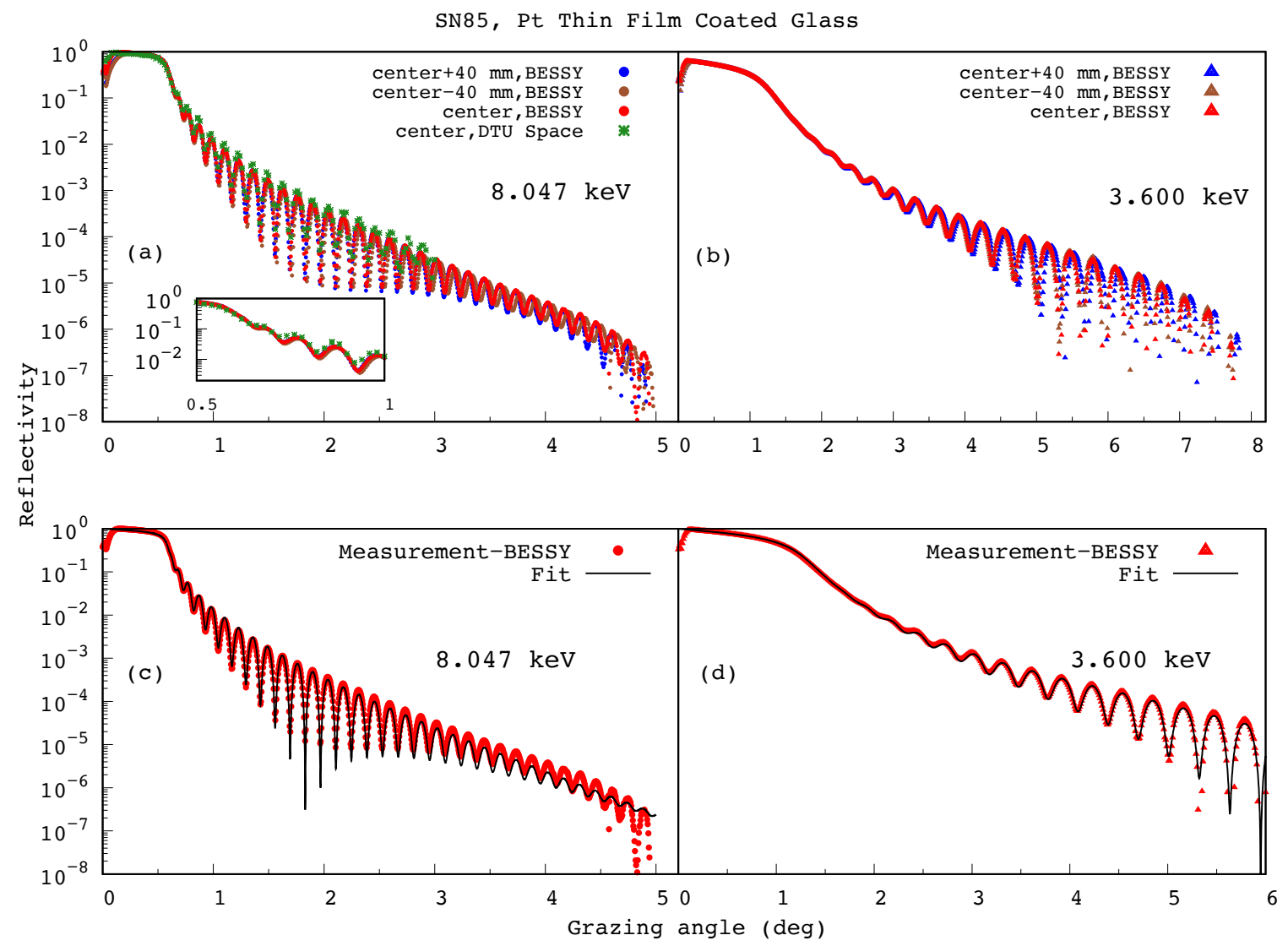

Figure 4: Measured angle scans at different positions on the Pt coated glass at (a) $8.047 \mathrm{keV}$ (b) $3.600 \mathrm{keV}$. Inset shows the zoomed-in $8.047 \mathrm{keV}$ plot in low-angle region. Overlapping Kiessig fringes confirm the thickness uniformity in the sample. The best-fit curve for the center position measurement of the (c) $8.047 \mathrm{keV} \mathrm{XRR} \mathrm{and}$ (d) $3.600 \mathrm{keV}$ XRR. The fit parameters are listed in Table 2.

data for the three positions at $8.047 \mathrm{keV}$ and $3.600 \mathrm{keV}$ indicating a very good horizontal thickness uniformity. This thickness uniformity is an important factor for the scans to be performed at various angles and consequently having different beam footprints. The experimental reflectance curves were fitted using the the IMD software ${ }^{13}$. The best fit model of the XRR measurement for $8.047 \mathrm{keV}$ and $3.600 \mathrm{keV}$ are depicted in Figures $4 \mathrm{c}$ and $4 \mathrm{~d}$, respectively. There is a good agreement between the results obtained from two energies measured at different facilities, see Table 2 .

By using the major advantage of energy tunability of synchrotron radiation, we obtained a reflectance as a function of energy. Three XRR spectra of the Pt coated glass sample are shown in Figure 5a. The measurements were performed at a grazing angle of $0.6^{\circ}$. As can been seen from the linear and the logarithmic scales (shown in the inset to Figure 5a) all three spectra obtained from three positions are identical in the entire energy range, confirming the coating uniformity across the sample.

The fitted thickness and roughness values reveal that the samples are homogeneous with a $\sim 30 \mathrm{~nm}$ Pt layer with roughness smaller than $0.5 \mathrm{~nm}$, also listed in Table 2. The fitted thickness of the witness and the glass samples are 30.2 and $30.5 \mathrm{~nm}$, respectively. The Pt thin film coated on glass is slightly thicker than the witness sample which is due to the thickness of the glass substrate $(17 \mathrm{~mm})$ while the Si wafer is $\sim 1 \mathrm{~mm}$ thick. Thus, the glass substrate was about $16 \mathrm{~mm}$ closer to the Pt target in the chamber and was exposed to more sputtered 
Table 2: Derived parameters from best fitting models of the Pt coated glass SN85 and the witness sample si6965. In the energy XRR model, an overlayer consisting of CHO with fixed density of $1.0 \mathrm{~g} / \mathrm{cm}^{3}$ and fitted value of $1.2 \mathrm{~nm}$ for thickness has been considered.

$\dagger$ The sensitivity of the energy XRR model to the substrate roughness value is rather low. A better estimation of this parameter can be done using an angle scan.

\begin{tabular}{lllllll}
\hline \hline Sample ID & XRR scan & Facility & $\begin{array}{l}z(\mathrm{~nm}) \\
\mathrm{Pt}\end{array}$ & $\begin{array}{l}\sigma(\mathrm{nm}) \\
\mathrm{Pt}\end{array}$ & $\begin{array}{l}\sigma(\mathrm{nm}) \\
\text { Substrate }\end{array}$ & $\chi^{2}$ \\
\hline SN85 & Angle scan: 8.047 keV & DTU Space & 30.5 & 0.32 & 0.35 & $9 * 10^{-3}$ \\
SN85 & Angle scan: 8.047 keV & BESSY & 30.5 & 0.46 & 0.23 & $5 * 10^{-3}$ \\
SN85 & Angle scan: $3.6 \mathrm{keV}$ & BESSY & 30.6 & 0.49 & 0.24 & $5 * 10^{-3}$ \\
SN85 & Energy scan: $3.4-10 \mathrm{keV}$ & BESSY & 29.8 & 0.38 & $0.57^{\dagger}$ & $6 * 10^{-5}$ \\
\hline Witness si6965 & Angle scan: 8.047 keV & DTU Space & 30.0 & 0.44 & 0.25 & $5 * 10^{-3}$ \\
Witness si6965 & Angle scan: 8.047 keV & BESSY & 30.2 & 0.41 & 0.23 & $5 * 10^{-3}$ \\
\hline \hline
\end{tabular}
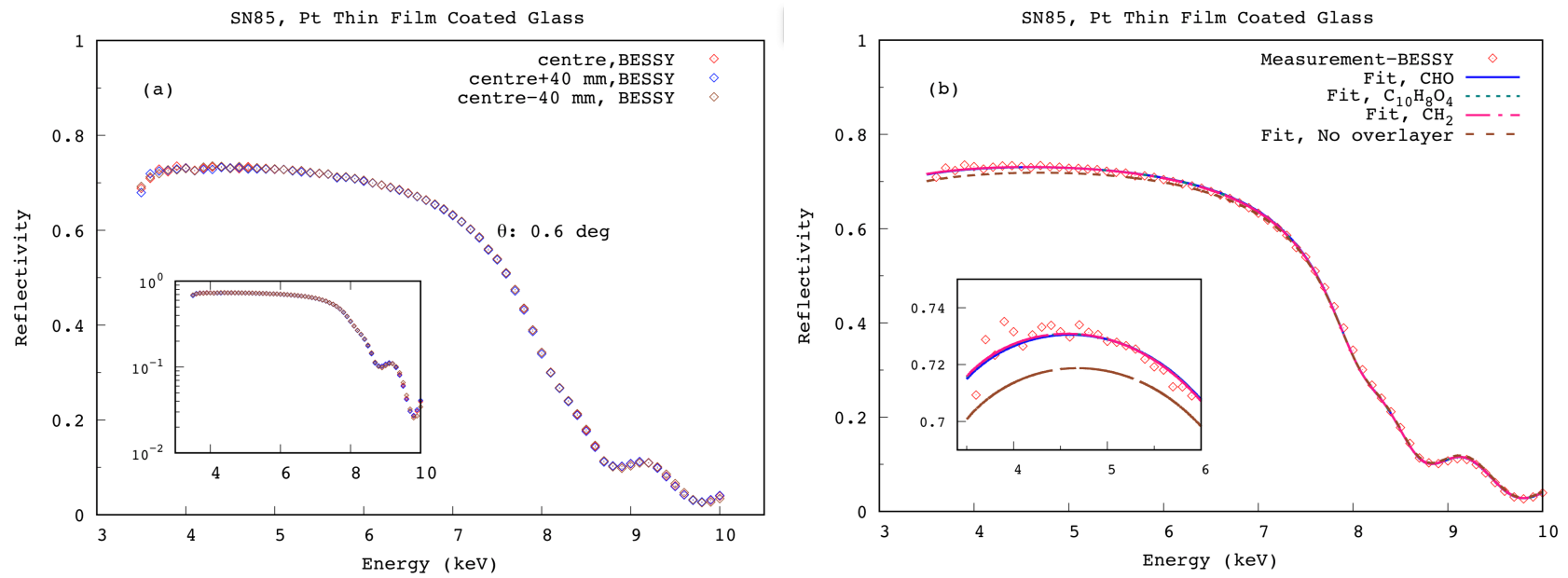

Figure 5: (a) Energy scans XRR at $0.6^{\circ}$ of the Pt coated glass, SN85, measured at BESSY II. (b) XRR of the centre position together with several fit models

Pt particles. The glass substrate roughness of $0.2-0.3 \mathrm{~nm}$ is examined through fits to several angle scans XRR measurements. However, fit to the energy measurement gives a higher value of $\sim 0.6 \mathrm{~nm}$. The model for the energy scan considers the overlayer parameters of: fixed C:H:O ratio of 1:1:1, fixed density: $1.0 \mathrm{~g} / \mathrm{cm}^{3}$, and fitted thickness of $1.2 \mathrm{~nm}$. The corresponding XRR data together with the fit are shown in Figure 5b. According to the simulation analysis, the effect of substrate roughness leads to a more significant change in angle scans than the energy scans. In an XRR model, mainly the high-energy regime of an energy spectrum ( $\sim 8 \mathrm{keV}$ and higher) show visible changes to substrate roughness variation. The top layer ( in this case $\mathrm{Pt}$ ) roughness affects the low-energy regime as well as the high energy. Perhaps, using angle scan XRR to determine substrate roughness is a more accurate way where both the slope and the oscillation amplitude of the curve are correlated to substrate roughness and small changes can be seen clearly. Thus, performing XRR measurement as functions of angle and energy are complementary which would provide a better understanding of the mirror structure. Furthermore, the XRR measurements indicate a higher roughness for the glass substrate compared to the optical profiler at $633 \mathrm{~nm}$, resulting in $0.1 \mathrm{~nm}$ reported by the manufacturer.

\subsection{Overlayer investigation}

Hydrocarbon contamination overlayer consisting of light elements is known to appear on samples when exposed to the atmosphere. Figure 5b presents several fits using four different models assuming either no overlayer or 
overlayers of different density and ratio of $\mathrm{C}, \mathrm{H}$, and $\mathrm{O}$. The presence of the hydrocarbon layer is visible in energy range below 6-7 keV. This can be better seen in the inset. In that respect, fitting using different combinations of $\mathrm{C}, \mathrm{H}$, and $\mathrm{O}$ results in nearly identical fit curves and similar Pt thickness and roughness values, results provided in Table 3. The given density values are from the CXRO optical constant database ${ }^{13,14}: \mathrm{CH}_{2}: 0.90 \mathrm{~g} / \mathrm{cm}^{3}$ and $\mathrm{C}_{10} \mathrm{H}_{8} \mathrm{O}_{4}: 1.38 \mathrm{~g} / \mathrm{cm}^{3}$. In the case of fitting with a $\mathrm{CHO}$ overlayer (C:H:O $=1: 1: 1$ ), the overlayer density and thickness parameters are not constrained as these are dependent parameters. Density is close to the upper limit of the defined fitting range, consequently lowers the overlayer thickness. For example, three sets of fitted values for the overlayer obtained: (1) $0.3 \mathrm{~nm}$ thick with density of $5.0 \mathrm{~g} / \mathrm{cm}^{3}$ and (2) a $0.7 \mathrm{~nm}$ thick with density of $2.0 \mathrm{~g} / \mathrm{cm}^{3}$, and (3) $1.2 \mathrm{~nm}$ thick with density of $1.0 \mathrm{~g} / \mathrm{cm}^{3}$. The latter one is close to the rest of the models using $\mathrm{CH}_{2}$ and $\mathrm{C}_{10} \mathrm{H}_{8} \mathrm{O}_{4}$ optical constants, moreover, considering high density of $5.0 \mathrm{~g} / \mathrm{cm}^{3}$ for hydrocarbon is not realistic. Therefore, we fixed the density parameter. All in all, our results are in good agreement with the reported $\sim 1.0 \mathrm{~nm}$ thick with density of $1.0 \mathrm{~g} / \mathrm{cm}^{3}$ overlayer on iridium mirrors ${ }^{15}$.

In brief, we determined that the Pt coated glass has a hydrocarbon overarlayer of about $1.0 \mathrm{~nm}$ thickness and a density of $\sim 1.0 \mathrm{~g} / \mathrm{cm}^{3}$, regardless of its exact stoichiometry and composition. Gaining a good understanding of the hydrocarbon overlayer, which is present in all our samples, benefits the general coating development by giving a more accurate data modelling and analysis of the mirror structure. The sample will be measured at $1.487 \mathrm{keV}$ at the new Low-Energy X-ray Reflectometer (LEXR) at DTU Space and the result could reveal more information about the hydrocarbon overlayer ${ }^{16}$.

Table 3: The derived fit parameters corresponding to the fitted curves shown in Figure 5b. The optical constants from CXRO database used for fitting using IMD software ${ }^{13,14}$. The fitting models consist of an overlayer and a Pt thin film on $\mathrm{SiO}_{2}$ substrate. The given roughness is the average roughness of these two layers, as these parameters are coupled in the fitting model. ${ }^{\star}$ denotes the fixed parameter (not constrained).

\begin{tabular}{llllllll}
\hline \hline XRR scan & Overlayer & $\begin{array}{l}\rho\left(\mathrm{g} / \mathrm{cm}^{3}\right) \\
\text { Overlayer }\end{array}$ & $\begin{array}{l}z(\mathrm{~nm}) \\
\text { Overlayer }\end{array}$ & $z(\mathrm{Pt})(\mathrm{nm})$ & $\begin{array}{l}\sigma(\mathrm{nm}) \\
\text { Overlayer } / \mathrm{Pt}\end{array}$ & $\begin{array}{l}\sigma(\mathrm{nm}) \\
\text { Glass substrate }\end{array}$ & $\chi^{2}$ \\
\hline $3.4-10.0 \mathrm{keV}$ & $\mathrm{CHO}$ & $2.0^{\star}$ & 0.7 & 29.8 & 0.43 & 0.58 & $6 \mathrm{E}-5$ \\
$3.4-10.0 \mathrm{keV}$ & $\mathrm{CHO}$ & $1.0^{\star}$ & 1.2 & 29.8 & 0.38 & 0.57 & $6 \mathrm{E}-5$ \\
$3.4-10.0 \mathrm{keV}$ & $\mathrm{C}_{10} \mathrm{H}_{8} \mathrm{O}_{4}$ & 1.38 & 0.9 & 29.8 & 0.41 & 0.58 & $6 \mathrm{E}-5$ \\
$3.4-10.0 \mathrm{keV}$ & $\mathrm{CHO}_{2}$ & 0.90 & 1.2 & 29.8 & 0.39 & 0.57 & $6 \mathrm{E}-3$ \\
$3.4-10.0 \mathrm{keV}$ & None & - & - & 29.9 & 0.39 & 0.48 & $2 \mathrm{E}-3$ \\
\hline \hline
\end{tabular}

\section{SUMMARY}

We designed, produced, and characterized a high quality reference mirror, i.e. a homogeneous Pt thin film coated on a very smooth and flat glass substrate. The sample was produced using DC magnetron sputtering facility at DTU Space. This study focused on XRR measurement results obtained at $8.047 \mathrm{keV}, 3.600 \mathrm{keV}$, and energy scan measurements in range of 3.4-10.0 keV. This sample will be used as reference for testing X-ray facilities that are being utilized for characterization of X-ray mirrors for the ATHENA telescope optics. Reflectivity measurements were performed at the $8.047 \mathrm{keV}$ XRR facility at DTU Space and at the FCM-PTB beamline at the BESSY II synchrotron radiation facility in Berlin. We conclude that about $30.5 \mathrm{~nm} \mathrm{Pt}$ with excellent uniformity and roughness close to $0.5 \mathrm{~nm}$ was deposited onto the super-polished glass substrate. A hydrocarbon surface contamination overlayer with $\sim 1 \mathrm{~nm}$ thickness is measured in the energy XRR spectrum. This sample will be tested and used as a reference sample during the next beamtimes and also in any other relevant facilities, e.g. the recently installed reflectometer LEXR at DTU Space, working at $1.487 \mathrm{keV}$.

\section{ACKNOWLEDGEMENT}

This work is supported by the European Space Agency under contract No. 4000102248/10/NL/PM, CCN3. 


\section{REFERENCES}

[1] Nandra, K., Barret, D., Barcons, X., Fabian, A., den Herder, J.-W., Piro, L., Watson, M., Adami, C., Aird, J., Afonso, et al., "The Hot and Energetic Universe: A White Paper presenting the science theme motivating the Athena+ mission," arXiv e-prints (2013).

[2] Dietrich, S. and Haase, A., "Scattering of x-rays and neutrons at interfaces," Physics Reports 260(1), 1 138 (1995).

[3] Gibaud, A. and Hazra, S., "X-ray reflectivity and diffuse scattering," Current Science 78(12), 1467-1477 (2000).

[4] Agustsson, J. S., Arnalds, U. B., Ingason, A. S., Gylfason, K. B., Johnsen, K., Olafsson, S., and Gudmundsson, J. T., "Electrical resistivity and morphology of ultra thin pt films grown by dc magnetron sputtering on SiO2," Journal of Physics: Conference Series 100(8), 082006 (2008).

[5] Aquilanti, G., Vaccari, L., Plaisier, J. R., and Goldoni, A., [Instrumentation at Synchrotron Radiation Beamlines], 65-104, Springer Berlin Heidelberg, Berlin, Heidelberg (2015).

[6] Harrison, F. A., Craig, W. W., Christensen, F. E., et al., "The Nuclear Spectroscopic Telescope Array (NuSTAR) High-Eenergy x-ray Mission," The Astrophysical Journal 770(2), 103 (2013).

[7] Louie, M. W. and Haile, S. M., "Platinum thin film anodes for solid acid fuel cells," Energy Environ. Sci. 4, 4230-4238 (2011).

[8] Thomsen-Schmidt, P., Hasche, K., Ulm, G., Herrmann, K., Krumrey, M., Ade, G., Stümpel, J., Busch, I., Schädlich, S., Schindler, A., Frank, W., Hirsch, D., Procop, M., and Beck, U., "Realisation and metrological characterisation of thickness standards below 100nm," Applied Physics A 78(5), 645-649 (2004).

[9] Soufli, R., Delmotte, F., Meyer-Ilse, J., Salmassi, F., Brejnholt, N., Massahi, S., Girou, D., Christensen, F., and Gullikson, E. M., "Optical constants of magnetron sputtered pt thin films with improved accuracy in the n- and o-electronic shell absorption regions," Journal of Applied Physics 125(8), 085106 (2019).

[10] Massahi, S., Ferreira, D. D. M., Christensen, F. E., Shortt, B., Girou, D. A., Collon, M., Landgraf, B., N. Barriere, M. K., Cibik, L., and Schreiber, S., "Development and production of a multilayer-coated x-ray reflecting stack for the Athena mission," Proc.SPIE 9905, 10 (2016).

[11] Vickery, A., Jensen, C. P., Christensen, F. E., Steenstrup, M. P., and Schønfeldt, T., "Collimated magnetron sputter deposition for mirror coatings," X-Ray Optics and Instrumentation 2008, 360-370 (2008).

[12] Krumrey, M. and Ulm, G., "High-accuracy detector calibration at the PTB four-crystal monochromator beamline," Nuclear Instruments and Methods in Physics Research Section A: Accelerators, Spectrometers, Detectors and Associated Equipment 467-468, 1175 - 1178 (2001). Proceedings of the 7th Int. Conf. on Synchrotron Radiation Instrumentation.

[13] Windta, D. L., " IMD Software for modeling the optical properties of multilayer films," Computers in Physics 12(4), 360-370 (1998).

[14] Henke, B., Gullikson, E., and Davis, J., "X-Ray Interactions: Photoabsorption, Scattering, Transmission, and Reflection at $\mathrm{E}=50-30,000 \mathrm{eV}, \mathrm{Z}=1-92, "$ Atomic Data and Nuclear Data Tables 54(2), $181-342$ (1993).

[15] Graessle, D. E., Soufli, R., Aquila, A. L., Gullikson, E. M., Blake, R. L., and Burek, A. J., "Iridium optical constants for the Chandra X-ray Observatory from reflectance measurements of 0.05-12 keV," Proceedings of SPIE - The International Society for Optical Engineering 5165 (2004).

[16] Henriksen, P. L., Christensen, F. E., Massahi, S., Ferreira, D. D. M., Svendsen, S., Jafari, A., and Shortt, B., "LEXR: A low-energy X-ray refectometer for characterization of ATHENA mirror coatings," Proc.SPIE 11119 (2019). 